\title{
REPRESENTAÇÕES DE INFÂNCIA E JUVENTUDE: FIOS ENTRETECIDOS EM NARRATIVAS DE PROFESSORAS
}

\author{
Iara Fernandes* \\ Maria Ângela R. Salvadori** \\ Vivian B. da Silva***
}

\begin{abstract}
RESUMO
O presente artigo analisa resultados de estudos em colaboração desenvolvidos entre docentes da Universidade São Francisco e professoras da Escola Municipal de Ensino Fundamental Prof ${ }^{a}$ Eliete Aparecida Sanfins Fusussi, em Itatiba, interior do estado de São Paulo, contando com apoio financeiro da FAPESP. O objeto nuclear das discussões desenvolvidas nesse âmbito são as representações de infância e juventude, questão que remete para maneiras como as professoras que participam do projeto vivem e discutem suas experiências a partir de textos diversos, no caso, memórias, fontes literárias, narrativas (auto)biográficas e filmes, usados durante as reuniões para mobilizar reflexões sobre o trabalho escolar. Nessa perspectiva, as páginas aqui apresentadas assinalam as possibilidades de espaços de investigação e formação que valorizam as vozes dos professores, procurando compreender os modos pelos quais eles estabelecem relações com a escola, os alunos e o conhecimento.
\end{abstract}

\footnotetext{
* Doutora em Matemática pela Universidade Estadual de Campinas e coordenadora do Curso de Matemática da Universidade de São Francisco. E-mail: iara. fernandes@saofrancisco.edu.br

** Doutora em Educação pela Universidade de Campinas e professora do Programa de Mestrado em Educação da Universidade de São Francisco. E-mail: maria. salvadori@saofrancisco.edu.br

*** Doutora em Educação pela Universidade de São Paulo e professora do Programa de Mestrado em Educação da Universidade de São Francisco. E-mail: vivian. silva@saofrancisco.edu.br
}

Educ. e Filos. Uberlândia, v. 23, n 45, p. 165-184, jan./jun. 2009. 
PALAVRAS-CHAVE: Trabalho docente. Infância e juventude. Narrativas autobiográficas. Estudos em colaboração

\begin{abstract}
The present article analyses cooperative study results made by professors and teachers of the Universidade São Francisco and Escola Municipal de Ensino Fundamental Prof ${ }^{a}$ Eliete Aparecida Sanfins Fusussi, a public grade school, in Itatiba, São Paulo, sponsored by FAPESP. The main object of the discussions were the representations of childhood and adolescence, an issue that brings the way the teachers who are participating of the program live their experiences and discuss them based on a variety of texts, such as memories, literary sources, autobiography and films used during their meetings to make them reflect about their works at school. Under this perspective, the pages that are presented here can show the possibilities for investigation and formation which give value for the teachers'voices trying to understand the way they establish relations with the school, the students and knowledge.
\end{abstract}

KEYWORDS: Teacher's work. Childhood and youth. Autobiography. Cooperative studies

"O narrador, o que conta a memória coletiva, está todo brotado de pessoinhas."

(Eduardo Galeano, A paixão de dizer. In. O livro dos abraços. 2.ed. Porto Alegre: L\&PM, 2007, p. 18.)

O presente artigo analisa resultados de estudos em colaboração desenvolvidos entre docentes da Universidade São Francisco e professoras da Escola Municipal de Ensino Fundamental Prof $^{a}$ Eliete Aparecida Sanfins Fusussi, em Itatiba, interior do 
estado de São Paulo, contando com apoio financeiro da FAPESP. ${ }^{1}$ O objeto nuclear das discussões desenvolvidas nesse âmbito são as representações de infância e juventude, que, tal como se entende, está no cerne de situações institucionais, pois remete para os modos pelos quais os professores estabelecem relações com os alunos do ensino fundamental e com a realidade social da qual participam. O intuito do projeto, então, é partir dessa questão nuclear para criar espaços de reflexão e investigação sobre a prática docente, articulando-se a uma discussão sobre formação mais ampla, posto que atualmente boa parte da literatura especializada tem assinalado a necessidade de produzir saberes que considerem as experiências do magistério. Assim concebido, o projeto sustenta a produção de estudos em colaboração com os professores no exercício de seu ofício, bem como o desenvolvimento de discussões partilhadas com os colegas, tomando como pilares as experiências docentes e a escola como lugar de crescimento profissional permanente (NÓVOA, 1991). E é nessa perspectiva que docentes da universidade e da escola, integrantes do projeto, têm se reunido em encontros semanais durante os quais estudam e discutem aspectos variados do cotidiano escolar que envolvem desde a multiplicidade de experiências de vida de professores e alunos até campos de produção de conhecimento mais específicos. Daí ser possível afirmar que o projeto envolve uma produção conjunta de ensaios e tentativas. Há questões teóricas a serem discutidas e também aspectos deliberativos que assim são submetidos a um debate coletivo.

A concepção de um trabalho como esse poderia conduzir erroneamenteà idéia de um curso que os professores daUSF ofereceriam a docentes da rede pública municipal de ensino fundamental. De fato, as reuniões constituem-se como espaço de formação, já que são lugares

${ }^{1} \mathrm{O}$ projeto "Representações de infância e juventude na cultura escolar" é desenvolvido por 5 docentes da Universidade São Francisco e 20 professores da EMEF Eliete. Além das três autoras deste texto, participam, pela USF, as professoras Adair Mendes Nacarato e Regina Célia Grando. 
de estudo sobre a escola, os alunos e o trabalho docente. Entretanto, elas distanciam-se de práticas de formação tradicionalmente ministradas em cursos nos quais o principal objetivo é dotar o professor de meios, regras e métodos que o capacitem a ser bem sucedido no ofício de ensinar. Se assim fosse, a universidade se aproximaria da escola para recomendar os procedimentos que poderiam ser aplicados em sala de aula ou para teorizar o ensino. Mas as reuniões não se organizam como disciplinas que partem dos temas de diferentes domínios do pensamento, do conhecimento e da arte, apresentando-se o ofício do magistério como uma prática dedutível dos saberes disciplinares. No projeto, o movimento é diverso porque a partir do tema nuclear referente às representações sobre infância e juventude - as professoras falam sobre suas próprias experiências e os modos pelas quais seus trabalhos estão engendrados na vida da escola. São as questões assim construídas que mobilizam pesquisas e estudos desenvolvidos em diversas áreas, como a filosofia, a história, a sociologia ou a psicologia, apenas para citar algumas das possibilidades que se colocam. Assim, o lugar ocupado pelos professores universitários no projeto não é o de docentes de um curso, pois todos discutem seu trabalho e assinalam aspectos decisivos para a compreensão do mesmo.

Uma alternativa como essa não é original no conjunto das produções sobre formação docente. A necessidade de os professores pensarem sobre o seu ofício é um princípio que vem sendo discutido em boa parte dos textos publicados a partir dos anos 1980, e sobretudo dos anos 1990, no caso brasileiro, que destacam a questão da memória e da autobiografia na formação docente. Uma das coletâneas sobre o tema mais lidas entre nossos educadores e pesquisadores foi organizada por A. Nóvoa e M. Finger, intitulandose $O$ método (auto)biográfico e a formação (1988). Na ocasião, estiveram reunidos textos de vários autores europeus que já vinham se dedicando ao estudo dessas questões. Alguns anos mais tarde, em 1997, outra coletânea foi publicada em Portugal, também sob a coordenação de Nóvoa e incorporando um artigo de Goodson que se 
tornou referência para iniciativas de - segundo palavras do próprio autor - dar voz aos professores. Tal expressão é ilustrativa pois, no quadro dos interesses que motivaram o conjunto das produções sobre memória e autobiografia, esteve o reconhecimento de que, comumente, os professores e suas práticas foram aspectos pouco enfatizados na construção de saberes que fundamentam o seu ofício. Os discursos do Estado e dos especialistas, entre os quais podemos destacar pesquisadores, médicos, psicólogos, juristas e pedagogos, tiveram mais visibilidade na literatura educacional e essa perspectiva orientou cursos realizados pelos professores, conformando, inclusive, aquilo que eles costumam esperar da produção acadêmica.

Isso explica uma dificuldade recorrente na definição do projeto, o que é, por si só, um desafio, porque as professoras da EMEF Eliete, até então, conheceram propostas de estudo em moldes disciplinares, o que caracterizou não só a sua formação como também a da categoria docente como um todo em cursos de Pedagogia, Licenciatura ou até mesmo em alguns programas de educação continuada. No caso brasileiro, e durante meados do século XX, por exemplo, o caráter pragmático dos cursos de formação de professores foi notável na valorização de técnicas, planos e fórmulas ensinados para serem reproduzidos em sala de aula (CATANI, 2001). Tradicionalmente percorrida pelos professores em sua trajetória de formação, essa modalidade de caminho ajuda a entender a tendência em se esperar da produção acadêmica conhecimentos a partir dos quais possam ser deduzidas alternativas concretas de trabalho na escola. Disso decorre outra questão, pois durante as reuniões, quando as professoras da EMEF Eliete falaram sobre suas experiências, assinalaram temas presentes no cotidiano de seu trabalho e produziram escritos que compreenderam desde textos sobre suas histórias de vida ou sobre os encontros com os professores da USF e sobre as referências discutidas nessas ocasiões. Vale lembrar que não houve um único padrão de produção estabelecido para todas as professoras participantes do projeto. Elas estão organizadas em 
grupos distribuídos em dias diferentes da semana, contando com a colaboração de diferentes professores da USF. Além disso, algumas delas participam do projeto desde o ano passado e há outros grupos nos quais a maior parte ingressou em fevereiro de 2007. Não obstante a multiplicidade de momentos e interesses das professoras, o grupo apresenta algumas características comuns nas formas pelas quais representam o magistério, muito freqüentes nas suas narrativas relativas à formação, trabalho e cotidiano escolar.

As narrativas orais e escritas das professoras permitem, portanto, identificar a utilização de determinados mecanismos discursivos. Sempre que tratam de desafios impostos ao seu trabalho, por exemplo, tendem a produzir textos que dizem como deve se proceder diante de casos específicos ou a encontrarem uma única causa da qual todas as dificuldades da escola teriam origem. Durante boa parte das reuniões, as professoras referem-se a questões de indisciplina, associando a vida escolar de alguns alunos às relações que eles mantêm com seus pais, irmãos ou avós. Neste sentido, observa-se recorrentemente uma análise bastante determinista que ora explica a indisciplina como resultante de heranças quase genéticas, ora como conseqüência do "meio" no qual vivem os alunos; em outras palavras, as professoras produzem análises que implicam em determinismo biológico ou social, o que muitas vezes se confronta com o próprio sentido que dão ao seu trabalho, a saber, a possibilidade da mudança via educação. A relação entre escola e família é uma questão recorrentemente discutida nos encontros e tem nos motivado a estudar os textos produzidos por Maria Helena Patto (2000) para tratarmos de questões mobilizadas durante as reuniões.

Outra característica bastante constante da fala e da escrita das professoras é a individualização da própria experiência, desconsiderando os vínculos entre suas trajetórias de vida e os contextos sociais e históricos mais amplos. Essa tendência evidenciase principalmente quando elas tratam de si usando a primeira pessoa do singular, sem deixar transparecer suas próprias experiências 
como experiências social e historicamente construídas. Em muitos encontros, professoras falaram de sua solidão na escola, expressa nos momentos de dificuldade com os quais devem lidar muitas vezes sem apoio dos colegas e também nas ocasiões em que são acusadas de não atingirem sucesso no ensino. Isso conduz a questionar de que maneira a formação docente, tal como tradicionalmente encaminhada, tem favorecido a percepção desse trabalho ao privilegiar o ensino de determinadas técnicas ou de saberes teóricos a partir dos quais, conforme se acredita, poderiam ser deduzidas alternativas de trabalho em sala de aula.

Num ensaio de análise sobre essas questões, assinalam-se aqui algumas das características desses relatos como dinâmicas de funcionamento da memória docente, favorecidos por um processo de formação e de constituição histórica da profissão. Mas convém realizar um exame mais detido sobre essas questões, atentando para o modo como elas se configuram em documentos produzidos ou vistos pelas professoras quando desenvolveram reflexões sobre suas experiências. Nessa perspectiva, apresentaremos a seguir dois recortes específicos deste trabalho que aparecem nas memórias que elas escreveram e nas imagens que, via cinema, mobilizaram para tratar de sua profissão.

\section{Imagens de si e do outro em fios entretecidos pelas professoras}

Nas construções sempre contemporâneas da memória ${ }^{2}$, os professores que participam do projeto reiteram constantemente a

\footnotetext{
${ }^{2}$ No âmbito deste texto não será possível discutir mais amplamente o conceito de memória com o qual trabalhamos. Entretanto, cumpre observar que pensamos a memória como processo constante de reconstrução do passado a partir de situações e vivências sempre contemporâneas. Distanciamo-nos, portanto, daqueles que concebem a memória como capacidade cognitiva inata para aproximarmo-nos de uma memória que é sempre a narrativa de si na relação com o outro. Esta perspectiva pode ser estudada, dentre tantos outros, em BOSI, Ecléa. Memória e sociedade, lembranças de velhos. São Paulo: TA Queiroz, 1979.
} 
idéia da ascensão social via educação; quase a totalidade deles faz do exercício atual da profissão uma conquista social, estabelecendo uma visão linear e progressiva do tempo que começa, repetidamente, com a dureza da infância, a pobreza da família, constituída em geral por pais não escolarizados, e, por fim, a conquista de uma profissão que, no imaginário das classes populares, reveste-se de simbolismos bastante próprios, ligados à posse de uma cultura letrada e acadêmica que funcionaria como um passaporte para um mundo melhor. Nos textos das professoras, esta concepção, ela própria forjada pela sociedade liberal moderna, é assumida e valorizada como traço identitário. Assim, por exemplo, a professora Fernanda escreveu:

Sempre estudei em escolas públicas, pois nunca tivemos condições para que fosse diferente [...]. Meus pais não são estudados; meu pai trabalhou a vida toda na fábrica e minha mãe como merendeira em escolas [...]. Em 2001 ingressei na faculdade e fui tomando gosto pelos estudos. Comecei a levar a sério e completei a faculdade nos quatro anos previstos, com muitos elogios pela grande participação nos anos em que lá estive, muito bem aproveitados [...]

Do mesmo modo, a professora Aline também destacou o apoio incondicional dos pais que, não tendo freqüentado a escola, percebiam o conhecimento como riqueza e patrimônio. Em uma escrita carregada de emoção e saudade, ela afirmou:

[...] A partir daí, resolvi fazer Letras e meus pais me apoiaram e ajudaram nos estudos. Jamais esqueci as palavras de meu pai a um amigo quando faltava pouco para acabar a faculdade e ele, por sua vez, já estava vivendo seus últimos dias de vida devido a um câncer no pulmão: 'fico triste por não poder estar presente na formatura da minha filha que será professora!' Encheu os olhos d'água e continuou: 'eu não tive estudos, não deixarei herança, mas uma coisa ninguém tirará dela... sua profissão, uma bela profissão'. 
[...] E hoje, trabalhando como tal, vejo que é uma profissão difícil, competitiva e que cada vez mais está sendo desvalorizada. Mas já passei por muitas dificuldades e não costumo desistir fácil.

A idéia de ascensão social via aquisição de uma cultura letrada, acadêmica e urbana fica muito evidente na fala da professora Marcela. De origem rural, Marcela via a escola como lugar de progresso, em oposição ao campo, símbolo do atraso:

À medida que o tempo foi passando, comecei então a encarar as coisas de outra maneira; comecei a perceber que a vida rural só era interessante quando não se tinha outro compromisso; aquilo começou a me parecer muito chato, um atraso de vida [...] Eu valorizava, agora, as pessoas de aparência intelectual, dotadas de um conhecimento que ultrapassava seus cotidianos e passei a ver a vida que eu levava como primitiva, apenas para a subsistência [...] Assim, a escola me trouxe conhecimento, valorização da não alienação, relações sociais diversas e auto-conhecimento. E cada vez mais fui mudando o meu estilo de ser, ou melhor, buscando o melhor estilo dentro de mim.

Ao final de seu texto, a professora Marcela registra:

Eu certamente não imaginava, quando pequena, que a menina irresponsável tornar-se-ia uma pessoa dedicada e afetiva para com seus alunos [...] A partir daí, então [...], eu sabia o que faria pelo resto de meus dias, aquilo a que eu me dedicaria para sempre, com vontade, com amor [...]

Um outro aspecto recorrente na memória dessas professoras são alguns dos rituais escolares, particularmente os momentos de formatura, emblemáticos destas conquistas. Se, de um lado, a recorrência de tais lembranças consolida uma imagem positiva de si, 
por outro, indica que a escola aparece muito mais por conta de seus resultados finais do que pelos processos contínuos de aprendizagem. Assim, ao enfatizarem os momentos de formatura, outorgando-lhes contornos gloriosos, a memória contribui para a constituição de um sujeito próprio; contudo, simultaneamente, tal sujeito desconhece - ou abandona neste momento - um outro significado deste ritual, aquele que fortalece a tendência de se pensar os resultados escolares em termos meritocráticos e individuais. Ainda no que se refere aos rituais de formatura, cabe notar a força da lembrança dos ritos religiosos naqueles momentos que, entendemos, também são indícios de uma permanência que aproxima a prática do magistério a uma noção religiosa de prática do bem. Os textos reproduzidos a seguir, das professoras Carla e Norma, respectivamente, são indícios dessa ambigüidade:

[...] Não posso deixar de falar da minha formatura. Iniciou-se com uma missa em Ação de Graças na Basílica de Nossa Senhora do Belém... que gelo na barriga. Fui escolhida para fazer uma das leituras, quase morri, mas uma das professoras me chamou de lado, me fez ler, pediu que tivesse calma e imaginasse que estava na sala de aula fazendo uma das leituras orais, o que me deu um pouco mais de alívio. Entramos e chegou a grande hora: ao subir no altar, como não estava acostumada com salto alto, quase caí. A risada foi geral e eu me descontraí. Ao terminar a celebração, iniciaram as entregas dos diplomas e premiações e naquele ano havia um prêmio especial, de Honra ao Mérito, para o aluno que participou mais ativamente de tudo que tinha na escola e, para minha supresa, fui a escolhida.

Minha formatura guardo muito bem na memória. Guardo também a fotografia que foi tirada com todos os formandos, direção e professores convidados para o evento. Depois da cerimônia religiosa, fomos jantar no restaurante Laço de Ouro em Itatiba. Que delícia!!! 
Em um outro momento do projeto, as professoras foram convidadas a selecionar filmes que, em suas opiniões, seriam significativos quanto ao modo com que abordam a escola e o seu trabalho. A partir daí, organizados em duplas ou individualmente, selecionaram alguns títulos e escolheram passagens para serem assistidas e discutidas coletivamente. Não houve qualquer avaliação da seleção de filmes feita pelos professores da Escola Eliete no sentido de aproximarem mais ou menos da realidade, ou seja, não se colocou nenhuma preocupação com o caráter verídico das narrativas fílmicas. Isto porque, entendemos, o produto audiovisual é sempre um documento de sua época, mesmo que a história que ele conte não possua um sentido explícito de realidade. Em outras palavras, não havia uma preocupação com a fidelidade dos fatos narrados nas películas e interessava, fundamentalmente, discutir a linguagem, o contexto e as próprias razões da escolha (CAPELATO et al, 2007).

No total, dez filmes foram selecionados, a saber: "O clube do imperador" (EUA, 2002), "Código de honra" (EUA, 2003), "O sorriso de Monalisa" (EUA, 2003), "A corrente do bem" (EUA, 2000), "Mentes perigosas" (EUA, 1995), "Encontrando Forrester" (EUA, 2000), "Sociedade dos poetas mortos" (EUA, 1989), "A voz do coração" (França, 2004), "Ao mestre com carinho" (Inglaterra, 1967) e "O Triunfo" (EUA, 2006). O que as professoras contam de si e de suas visões de mundo ao selecionarem tais filmes?

Uma rápida síntese permite estabelecer traços bastante comuns entre os filmes escolhidos. Em primeiro lugar, há uma tendência à seleção de películas nas quais os papéis de alunos, professores e direção aparecem de modo bastante distinto e cristalizado. Assim, em parte significativa dos filmes, o diretor é aquele que se coloca na contramão do professor que, apesar das muitas dificuldades, pretende modificar aspectos do cotidiano escolar. Esta oposição entre professor e diretor, tão demarcada pelos professores/pesquisadores da escola, aparece nos filmes "Ao mestre com carinho", "O sorriso de Monalisa", "A voz do coração" e "Sociedade dos poetas mortos", 
por exemplo. Entende-se aqui que, ao enfatizarem este aspecto, os professores procuram também, ainda que de modo indireto, chamar a atenção para os problemas que esta relação de poder cotidianamente lhes coloca. Ao fazê-lo, estabelecem dois modelos de conduta que, em geral, se constituem em importantes referências sobre as representações de um e de outro presentes na cultura escolar: de um lado, o diretor cruel, preso aos aspectos burocráticos de seu trabalho, rude em relação aos alunos, conservador; de outro, o professor dedicado, generoso, próximo dos alunos, em luta contra as injustiças da instituição. A compreensão destes dois arquétipos, evidentemente, só pode ser pensada pela relação que estabelecem entre si e, presume-se, revela as dificuldades encontradas por ambos no exercício de sua profissão.

Um outro elemento de similaridade entre os vários filmes selecionados é uma condição quase "redentora" dos professores. É fácil perceber, neste sentido, que permanece muito forte entre os docentes/pesquisadores uma espécie de ethos salvacionista que remonta a antigas representações do magistério. Não é à toa que, em boa parte dos filmes, o professor é o responsável por uma transformação interna do aluno, que o promove tanto em termos escolares quanto em termos sociais. Assim, por exemplo, em "Encontrando Forrester", é o professor que estimula o crescimento intelectual do aluno e, além disso, o protege diante das ameaças de uma sociedade preconceituosa e racista; em "A voz do coração" é também um professor o responsável pelo fim da violência com a qual os alunos do internato eram anteriormente tratados. Esta situação se repete, ainda, nos filmes "A corrente do bem", "Mentes perigosas" e em "O Triunfo". Estranhamente, entretanto, foi escolhido um filme ("O clube do imperador") no qual o professor não consegue "modificar" o aluno que, mesmo depois de adulto, continua a usar a trapaça e a mentira para conquistar dinheiro e prestígio. Ao justificarem sua escolha, entretanto, os professores afirmaram que, longe de querer indicar o fracasso profissional do referido professor, 
a tratava-se de ressaltar valores tais como abnegação, bondade e persistência com os quais orientam sua conduta.

Esse trabalho com os filmes revela alguns dos valores que este grupo de professores/pesquisadores considera positivos para o exercício de sua profissão; neste processo, conhecimentos específicos, de matriz mais científica e/ou curricular são deixados em um absoluto segundo plano. As qualidades fundamentais são essencialmente ligadas ao campo da moral: solidariedade, bondade, paciência, persistência, abnegação e, por vezes, até mesmo a resignação. $O$ bom professor se define antes por atributos de sua personalidade e caráter do que por seus conhecimentos específicos. Em parte significativa desses filmes, é ele quem conduz o grupo numa espécie de "messianismo" educacional. As palavras da professora Marcela, em seu registro escrito sobre o filme por ela escolhido ("Mentes Perigosas") indicam claramente esta idéia:

O ensino e a arte de lecionar constituem não só uma profissão, mas também e principalmente instituem as primeiras noções de comportamentos, de atitudes, de relacionamentos e, enfim, de vida. Antes de tudo, então, ensinemos a vivência e aprendamos com ela.

Deste modo, a seleção feita pelos docentes destaca relações de afeto e seus "efeitos" sobre o cotidiano escolar e desempenho dos alunos; mostra, ainda, a pertinência de estudos relativos à formação de professores nos quais a questão do desvelo e do cuidado com o outro, enquanto componentes de gênero, são bastante esclarecedoras do sentido da escolha profissional e de seus desdobramentos (SOUSA et al., 1996).

Entende-se, por fim, que os filmes foram escolhidos menos por espelharem dificuldades eventualmente encontradas pelos professores durante seu trabalho e mais por apresentarem um perfil do professor recheado de valores que compartilham e/ou julgam socialmente bem aceitos. Esta representação do trabalho e da figura 
docente que aparece nos filmes é fortalecida pela situação na qual foram exibidos, pois assisti-los coletivamente significa compartilhar uma situação social que não ocorre, por exemplo, com a leitura solitária de um livro. A seleção, assim, envolveu não apenas o gosto pessoal do professor, mas os contextos de recepção da mensagem transmitida pelo vídeo.

Além das representações sobre o professor, existem aquelas ligadas aos alunos. Nesta direção, predominam dois modos opostos, mas igualmente estigmatizantes, de pensá-los: em parte dos filmes, os alunos são vítimas à espera de alguém que os "salve"; em outra parte, são rebeldes, indisciplinados, perigosamente livres e, nestes casos, estão à espera de alguém que os transforme, molde, acalme. A vitimização do aluno, seja por uma injusta situação social, familiar, de gênero, de etnia ou, ainda, pela autoridade desenfreada de um diretor, hiperdimensiona as possibilidades do trabalho docente, muito mais presas ao caráter e à moral do que ao conhecimento; o seu oposto, a idéia da rebeldia, está indissociavelmente atrelada à juventude. Neste sentido, é preciso pensar o cinema enquanto um dos lugares de produção desta representação de juventude associada à delinqüência e a rebeldia. Simultaneamente, é preciso perceber a diferença entre a percepção dos professores sobre suas próprias juventudes, harmonizadas pelas construções da memória, e a juventude de seus alunos, alvo de todo um investimento educativo ligado ao controle e à repressão.

As palavras da professora Lúcia, durante a exibição dos filmes, indicam claramente a permanência desta idéia do professor como alguém capaz de fazer a diferença na vida das crianças e jovens que educa, "Por mais que tropecemos, o fardo de um professor é sempre esperar que o ensino mude o caráter de um garoto e, assim, mude também o seu destino."

Impossível não pensar, relendo as palavras de Lúcia, das teorias evolucionistas do século XIX e da própria noção do "fardo do homem branco", o europeu civilizado, em relação aos "bárbaros" 
habitantes dos continentes africano e asiático. Embora não se trate aqui de afirmar um preconceito intrínseco por parte dos professores, cumpre notar que há a permanência de uma visão que faz do magistério uma missão civilizatória e redentora.

Por fim, uma nota relativa ainda às questões de gênero. Dos dez filmes selecionados pelos professores, sete trazem como personagem central da trama professores homens, embora o grupo de trabalho do projeto seja constituído, em sua totalidade, por mulheres. Ainda que pesem as peculiaridades culturais relativas aos seus países de origem, este dado revela uma análise da docência na qual aspectos psicológicos se sobressaem frente a fatores sociais e históricos que conduziram a um processo de feminização do magistério. Dentre os filmes selecionados, não há produções nacionais, documentários ou películas ligadas ao chamado "circuito alternativo". Todas as produções são bastante hollywoodianas e as professoras não comentaram, de modo espontâneo, os possíveis significados desta insistente incidência de heróis masculinos numa profissão que se constituiu historicamente atravessada pelo campo do gênero.

\section{Considerações finais}

Nos últimos parágrafos deste texto, queremos problematizar as ambigüidades que caracterizam não apenas as memórias das professoras e os motivos que as levaram a escolher certos filmes, mas o próprio uso desses recursos nos processos de formação docente. Certamente, eles são percebidos como um caminho importante, capaz de criar espaços e condições para a construção e fortalecimento da identidade profissional. Por outro lado, esta busca pelo reconhecimento do sujeito professor e de seus discursos próprios não pode deixar de reconhecer as questões que perpassam estas falas que, muitas vezes, assumem como verdade uma visão romântica da profissão, que celebra relacionamentos pessoais e diminui o peso do conhecimento formal na escola. As lembranças 
que temos todos dos tempos de aluno estão carregadas de emoção e afetividade mas, na condição de professores e no contexto presente, não nos é possível abdicar da escola enquanto lugar fundamental de democratização do conhecimento historicamente produzido pela humanidade, certamente capaz de nos proporcionar uma melhor compreensão do mundo e de nós mesmos.

Por fim, entendemos ser importante refletir sobre os sentidos deste romantismo. Se é certo que ele vem carregado de nostalgia do antigo mestre, é igualmente certo que este desencanto atual representa uma forma de crítica e, deste modo, esta nostalgia do passado implica também em questionamentos do presente e proposições para o futuro. Assim, de algum modo, as narrativas de si e os reforços identitários que os trabalhos propostos no decorrer do projeto promoveram, sinalizam tanto para as vitórias da escola de massas no sentido da configuração do sujeito moderno quanto para a necessidade de repensar este inventário. Se o que se quer é dar voz aos professores (GOODSON, 1997), o estudo de questões como essas permite aos professores a reflexão sobre os modos pelos quais estabelecem relações com a escola, os alunos e o conhecimento, criando novos espaços de investigação e formação, diferentes daqueles tradicionalmente estabelecidos.

\section{Referências}

BOSI, Ecléa. Memória e sociedade, lembranças de velhos. São Paulo: TA Queiroz, 1979.

CAPELATO, Maria Helena et al. História e Cinema. São Paulo: Alameda, 2007.

CATANI, Denice Barbara . A didática como iniciação: uma alternativa no processo de formação de professores. In: A. D. Castro; Ana Maria Pessoa Carvalho. (Org.). Ensinar a ensinar: didática para a escola 
fundamental e média. São Paulo: Pioneira, 2001, p. 53-72.

GALEANO, Eduardo. In. O livro dos abraços. 2.ed. Porto Alegre: L\&PM, 2007.

GOODSON, Ivor F. Dar voz ao professor: as histórias de vida dos professores e o seu desenvolvimento profissional. In. NÓVOA (org) Vidas de professores. Porto: Porto Editora, 1997. p. 63-78.

NÓVOA, António (org.). Profissão professor. $2^{\mathrm{a}}$ ed. Porto: Porto Editora, 1991.

NÓVOA, António, FINGER, M. O método (auto)biográfico e a formação, Lisboa: Ministério da Saúde. Dep. dos Recursos Humanos da Saúde/Centro de Formação e Aperfeiçoamento Profissional, 1988.

PATTO, Maria Helena. A produção do fracasso escolar: histórias de submissão e rebeldia. SP: Casa do Psicólogo, 2000.

SOUSA, Cynthia Pereira de et. al. Memória e biografia, formação de mulheres e formação de professoras. Revista Brasileira de Educação, Rio de Janeiro, n. ${ }^{2}$, agosto 1996, p. 61-76.

\section{Filmografia}

A CORRENTE do bem (Pay It Forward). Direção: Mimi Leder. Produção: Peter Abrahms, Robert L. Levy e Steven Reuther. Roteiro: Leslie Dixon, baseado no livro de Catherine Ryan Hyde. Elenco: Haley Joel Osment; Kevin Spacey; Helen Hunt e outros. Estúdio: Warner Bros. / Bel Air Entertainment. Distribuição: Warner Bros EUA, 2000. (115 min), son. col. 
O CLUBE do Imperador (The Emperor's Club). Direção: Michael Hoffman. Produção: Marc Abraham e Andy Karsch. Roteiro: Neil Tolkin, baseado em curta-metragem de Ethan Canin Elenco: Kevin Kline; Emile Hirsch e outros. Estúdio Beacon Communications LLC / Fine Line Features / Horsepower Films / Liveplanet / Longfellow Pictures / Sidney Kimmel Entertainment Distribuição: Universal Pictures / UIP. EUA, 2002 . (109 min), son., col.

CÓDIGO de honra (School Ties). Direção: Robert Mandel, Produção: Paramount Pictures. Roteiro: Dick Wolf, Darryl Ponicsan. Elenco: Brendan Fraser; Matt Damon; Chris O Donnell; Randall Batinkoff e outros. Distribuição: Paramount Pictures do Brasil. EUA, 1992. (106 min), son. col.

ENCONTRANDO Forrester (Finding Forrester). Direção: Gus Van Sant. Produção: Sean Connery, Lawrence Mark e Rhonda Tollefson. Roteiro: Mike Rich. Elenco: Sean Connery; F. Murray Abraham; Robert Brown e outros. Estúdio: Columbia Pictures Corporation. Distribuição: Colmbia Pictures / Sony Pictures Entertainment .EUA, 2000. (135 min), son. col.

MENTES Perigosas (Dangerous Minds). Direção: John N. Smith. Produção: Jerry Bruckheimer e Don Simpson. Roteiro: Ronald Bass, baseado em livro de LouAnne Johnson. Elenco: Michelle Pfeiffer; George Dzundza; Courtney B. Vance e outros. Estúdio: Buena Vista Pictures / Hollywood Pictures / Don Simpson/Jerry Bruckheimer Films. Distribuição: Buena Vista International EUA, 1995. (99 min), son. col.

AO MESTRE com carinho (To Sir, with Love). Direção: James Clavell. Produção: Columbia British Productions, Columbia Pictures Corporation. Roteiro: E.R. Braithwaite. Elenco: Sidney Poitier; Christian Roberts; Judy Geeson; Suzy Kendall e outros. Distribuição: Columbia Pictures. Inglaterra, 1967. (105 min) son. col. 
SOCIEDADE dos Poetas Mortos (Dead Poets Society). Direção: Peter Weir. Produção: Steven Haft, Paul Junger Witt e Tony Thomas. Roteiro: Tom Schulman. Elenco: Robin Williams; Robert Sean Leonard; Ethan Hawke e outros. Estúdio: Touchstone Pictures. Distribuição: Buena Vista Pictures. EUA, 1989. (129 min), son., col.

O SORRISO se Monalisa (Mona Lisa Smile). Direção: Mike Newell. Produção: Elaine Goldsmith-Thomas, Paul Schiff e Deborah Schindler. Roteiro: Lawrence Konner e Mark Rosenthal. Elenco: Julia Roberts; Kirsten Dunst e outros. Estúdio: Columbia Pictures Corporation/ Revolution Studios/ Red Om Films Distribuição: Columbia Pictures/ Sony Pictures Entertainment EUA, 2003. (125 $\min )$, son. col.

O TRIUNFO (The Ron Clark Story/The Triumph). Direção: Randa Haines. Produção: Roteiro: Annie deYoung, Max Enscoe. Elenco: Matthew Perry; Judith Buchan; Hannah Hodson; Jerry Callaghan e outros. Estúdio: California Home Vídeo. Distribuição: California Home Vídeo. EUA, 2006. (120 min), son. col.

A VOZ do coração (Les Choristes). Direção: Christophe Barratier. Produção: Arthur Cohn, Nicolas Mauvernay e Jacques Perrin. Roteiro: Christophe Barratier e Philippe Lopes-Curval. Elenco: Gérard Jugnot; François Berléand; Jean-Baptiste Maunier; Jacques Perrin e outros. Estúdio: France 2 Cinéma/ Galatée Films/ Pathé Renn Productions/ Novo Arturo Films/ Vega Film AG / CP Medien AG. Distribuição: Miramax Films / PlayArte. França, 2004. (95 $\min )$, son. col. 